\title{
Editorial - botany in global history
}

\author{
William G. Clarence-Smith
}

A botanical theme emerged by chance from a confluence between submissions to the journal, rather than from any academic gathering. The three articles constituting this cluster survey different historical periods, are rooted in different geographical locations, and have diverse focal points. However, they all relate to the global dissemination of economically valuable cultigens and they all take up the question of international networks of scientists, connected by the pursuit of knowledge, while separated by the political ambitions of states and empires. Botanical gardens, or later agricultural experimental stations, were often nodal points in these processes of economic and scientific exchange.

Focusing on the central role of Russia in botanical relations between China and western Europe, Matthew Romaniello places the case study of rhubarb in the wider context of early modern scientific knowledge in Eurasia. The emphasis lay on discovering the medical properties of plants, on 'bioprospecting' as a form of 'botanical espionage', and on exporting dried and powdered preparations. The movement of seeds and seedlings lagged behind, whether because of legal controls over such transfers in a mercantilist era or because of practical impediments. Thus, growing rhubarb in western Europe only became possible in the late eighteenth century, and it was not until the nineteenth century that it was cultivated on a commercial scale.

John McAleer shows that, by the beginning of the nineteenth century, exchanges of live plant materials were opening up, with techniques of preservation over long distances improving, even before the invention of the Wardian case. Medical research continued, but interest in more widely economically useful plants was growing. Focusing on British possessions in the South Atlantic, the 'crossroads of Britain's maritime empire', McAleer places St Helena and the Cape of Good Hope at the heart of a global web of botanical connections. Scientists, settlers, traders, and visitors engaged in the collection and exchange of specimens. Officials also took part, albeit in a private capacity, for the British imperial state was little involved at this stage. The network was not necessarily centred on London, but linked diverse peripheries to each other, especially the South Atlantic to the Indian Ocean. This was not a 'hermetically sealed "British world"', however, for foreign countries and other empires participated, for example in the exchange of plant materials between Rio de Janeiro and Calcutta.

The first world agricultural census, compiled from 1925 to 1930, is the focus of Amalia Ribi Forclaz's article. By this time, scientific interest focused insistently on food security, after the First World War had disrupted trade and caused localized famines. Formally coming under the auspices of the International Institute of Agriculture in Rome, but largely funded and driven by the Rockefeller Foundation and the United States Department of Agriculture, 
the census was not finally published until 1938, and thus had little practical impact. However, the process of preparing the census involved much exchange of information. Leon Estabrook, the American project director, unofficially conceived of his tour of the world in 1926-29 as an opportunity to propagate visions of agricultural 'modernization'. This included scientific methods of seed and plant selection that had been pioneered in the US.

These three stories form part of two wider historical preoccupations. The evolution of agricultural 'commodity chains', consisting of distinct 'segments', is one of these. Botanical endeavour, resulting in the discovery and dissemination of new planting materials, has long been a vital link in such commodity histories. Together, the article also speak to the scientific aspects of the botanical pursuit, and in particular to the constitution of communities of like-minded researchers across the globe. This cluster is thus a contribution to fields of enquiry that are now attracting increasing attention. 